\title{
Efeito de fungicidas para o controle da Ramularia areola na cultura do algodoeiro
}

\author{
Liliane Oliveira Lopes ${ }^{1}$, Julian Junio de Jesús Lacerda ${ }^{2}$, Fabio Mielezrski ${ }^{2}$, Rafael Felippe Ratke ${ }^{2}$, Dalliane Nogueira \\ de Souza Lira ${ }^{1}$ e Leandro Pereira Pacheco ${ }^{3}$
}

\begin{abstract}
${ }^{1}$ Mestrado em Agronomia: Solos e Nutrição de Plantas, Universidade Federal do Piauí, Campus Professora Cinobelina Elvas, Rodovia Municipal Bom Jesus-Viana Km 01, Bairro Planalto Horizonte, Bom Jesus-PI, Brasil, 64900-000. ${ }^{2}$ Professor da Universidade Federal do Piauí, Campus Professora Cinobelina Elvas, Rodovia Municipal Bom Jesus-Viana Km 01, Bairro Planalto Horizonte, Bom Jesus-PI, Brasil, 64900-000. ${ }^{3}$ Professor da Universidade Federal de Mato Grosso, MT 270, km 06, Bairro Sagrada Familia, Rondonopolis-MT, Brasil, 78735-901
\end{abstract}

Autor para correspondência: Liliane Oliveira Lopes (liliane_ol@hotmail.com)

Data de chegada: 23/05/2016. Aceito para publicação em: 13/03/2017.

$10.1590 / 0100-5405 / 2203$

\section{RESUMO}

Lopes, L.O.; Lacerda, J.J.J.; Mielezrski, F.; Ratke, R.F.; Lira, D.N.S.; Pacheco, L.P. Efeito de fungicidas para o controle da Ramularia areola na cultura do algodoeiro. Summa Phytopathologica, v.43, n.3, p.229-235, 2017.

Entre as doenças que causam manchas foliares no algodoeiro, a mancha de ramulária tem se tornado importante em ambientes tropicais, porque as condições climáticas são favoráveis para o desenvolvimento do patógeno. Objetivou-se nesse trabalho avaliar o desempenho dos fungicidas difenoconazol, trifenil hidróxido de estanho, trifloxistrobina, protioconazol e mancozebe, isolados ou em misturas, no controle da mancha de ramulária no algodoeiro. O experimento foi conduzido na safra 2014/2015, em uma fazenda localizada no município de Sapezal, estado do Mato Grosso. O delineamento experimental foi em blocos casualizados e quatro repetições, com parcelas subdivididas no tempo. Foram realizadas sete avaliações de níveis de severidade da mancha da ramulária nos sete tratamentos. Os fungicidas foram aplicados oito vezes, em intervalos de 15 dias. Ao final do período experimental, foi avaliada a produtividade e a eficiência de controle dos fungicidas em comparação com a testemunha. A aplicação de fungicidas reduziu os danos de produtividade devido ao ataque do fungo Ramularia areola. $\mathrm{O}$ trifenil hidróxido de estanho, isolado ou em mistura com o difenoconazol permitiu maior controle da severidade da mancha de ramulária do que a combinação de trifloxistrobina + protioconazol com difenoconazol, ou difenoconazol com mancozebe.

Palavras-chave: Gossypium hirsutum, Ramularia areola, IDM, ditiocarbamatos.

ABSTRACT

Lopes, L.O.; Lacerda, J.J.J.; Mielezrski, F.; Ratke, R.F.; Lira, D.N.S.; Pacheco, L.P. Effect of fungicides on Ramularia areola control in the cotton crop. Summa Phytopathologica, v.43, n.3, p.229-235, 2017.

Among the diseases that cause leaf spots in the cotton crop, ramularia leaf spot has become important in tropical environments since the weather conditions are favorable to the pathogen development. The aim of this study was to evaluate the performance of fungicides difenoconazole, triphenyltin hydroxide, trifloxystrobin, prothioconazole and mancozeb, alone or in mixtures, in controlling ramularia leaf spot in the cotton crop. The experiment was carried out in the 2014/2015 crop season, at a farm located in Sapezal Municipality, Mato Grosso State. Experimental design was in randomized blocks with four replicates and split plot in time. Seven evaluations of ramularia spot severity levels were performed with seven treatments. Fungicides were applied eight times, at 15-day intervals. At the end of the experimental period, the yield and the control effectiveness of fungicides were evaluated in comparison with control. Fungicide applications reduced yield damage caused by the attack of the fungus Ramularia areola. Triphenyltin hydroxide alone or in combination with difenoconazole allowed greater control of ramularia spot severity than the combination of trifloxystrobin + prothioconazole with difenoconazole, or diphenoconazole with mancozeb.

Keywords: Gossypium hirsutum, Ramularia areola, DMI, dithiocarbamates

A mancha de ramulária, causada pelo fungo Ramularia areola G.F. Atk., 1890, forma assexual ou anamórfica e sexual ou teleomófica, Mycosphaerella areaola Ehrlich \&F.A. Wolf, 1932, é uma das doenças de importância econômica para o sistema de produção do algodoeiro no Brasil (13). Essa doença era considerada um problema fitossanitário secundário para o algodoeiro e só ocorria no final do ciclo da cultura. No entanto, com a adoção de cultivares mais produtivos e suscetíveis à doença, a mancha da ramulária passou a ser identificada também nos estádios iniciais da cultura, em torno de 60 dias após o plantio. A doença tem sido responsável por danos estimados em $30 \%$ da produção de algodão na região do cerrado, e de até $75 \%$ no estado do Mato Grosso (14).

$\mathrm{O}$ custo com defensivos químicos é muito alto na cultura do algodoeiro, ao considerar que de modo geral são necessárias pelo menos quatro a cinco aplicações durante o ciclo (23). No entanto, o controle da mancha de ramulária tem exigido número crescente de aplicações, não raro em torno de dez, o que pode ser um indício de resistência do patógeno ao uso repetido de um fungicida ou de fungicidas quimicamente relacionados que expressam um mecanismo comum de ação antifúngica $(6,8)$.

Alguns dos novos fungicidas introduzidos recentemente no mercado são fungicidas de sítio específico, atuam contra os agentes patogênicos num único local de ligação na via bioquímica, por exemplo, os inibidores da biossíntese de esteróis como triazóis, inibidores de respiração como as estrobilurinas e carboxamidas, e inibidores de biossíntese celulose tais como amidas de ácido carboxílico (10). 
A aplicação de fungicidas para o controle da mancha de ramulária no algodoeiro é iniciada imediatamente após a identificação das primeiras lesões nas folhas mais velhas, esta estratégia busca impedir ou retardar a epidemia e o aumento do inóculo no campo (20). O monitoramento constante da lavoura é importante, porque a dispersão do patógeno ocorre em um curto espaço de tempo, por meio do vento, da água da chuva ou de irrigação, como também por pessoas e máquina. $\mathrm{O}$ uso de cultivares suscetíveis à doença, como os genótipos de algodoeiro, Delta Opal, Makina e Sure Grow 821 contribui para a incidência nas regiões produtoras de algodão $(12,6)$.

Uma das alternativas para se manejar a resistência dos patógenos tem sido a utilização de combinações de fungicidas com diferentes modos de ação (fungicidas de alto risco de resistência com fungicidas baixo risco). Os fungicidas multissítios tais como o mancozeb tem sido bastante utilizado nas combinações. A aplicação de fungicidas, isoladamente ou em mistura para o controle da mancha de ramulária é necessária, principalmente quando as condições ambientais favorecem o progresso da doença, umidade acima de $80 \%$ e temperaturas na faixa de 17 a $30^{\circ} \mathrm{C}(11,8)$.

Diante do exposto, objetivou-se nesse trabalho avaliar o desempenho dos fungicidas difenoconazol, trifenil hidróxido de estanho, trifloxistrobina + protioconazol e mancozebe, isolados ou em misturas, no controle da mancha de ramulária no algodoeiro.

\section{MATERIAL E MÉTODOS}

O trabalho foi conduzido em lavoura comercial de algodoeiro, manejada no sistema de plantio convencional (SPC), na Fazenda Harmonia, distante a aproximadamente $22 \mathrm{~km}$ do município de Sapezal - MT. As coordenadas geográficas da área experimental são $13^{\circ} 48^{\prime} 55^{\prime \prime}$ $\mathrm{S}$ e $58^{\circ} 45^{\prime} 35^{\prime}$ ' O, com $581 \mathrm{~m}$ de altitude. A precipitação pluvial diária na fazenda, no decorrer da condução do trabalho, de janeiro a setembro de 2014, está apresentada na Figura 1.

O solo foi classificado como Latossolo Vermelho Distroférrico (17) e caracterizado quanto aos atributos químicos e físicos da camada de 0-0,20 m, cujos valores foram: $\mathrm{pH}\left(\mathrm{CaCl}_{2}\right)=5,4 ; \mathrm{M} . \mathrm{O}=2,8 \mathrm{~g} \mathrm{dm}^{-3} ; \mathrm{P}=$ $11,2 \mathrm{mg} \mathrm{dm}^{-3} ; \mathrm{H}+\mathrm{Al}=3,05 \mathrm{cmol} \mathrm{dm}_{\mathrm{c}}^{-3} ; \mathrm{K}=0,08 \mathrm{cmol} \mathrm{dm}_{\mathrm{c}}^{-3} ; \mathrm{Ca}=2,75$ $\mathrm{cmol}_{\mathrm{c}} \mathrm{dm}^{-3} ; \mathrm{Mg}=1,04 \mathrm{cmol}_{\mathrm{c}} \mathrm{dm}^{-3} ; \mathrm{SB}=3,88 \mathrm{cmol} \mathrm{dm}^{-3} \mathrm{e} \mathrm{V}=55 \%$, areia ${ }^{\mathrm{c}}=530 \mathrm{~g} \mathrm{~kg}^{-1}$, silte $=110^{\mathrm{c}} \mathrm{g} \mathrm{kg}^{-1}$ e argila $=360 \mathrm{~g} \mathrm{~kg}^{\mathrm{c}}$.

$\mathrm{O}$ delineamento experimental foi em blocos casualizados com parcela subdividida no tempo e quatro repetições. Foram avaliados sete tratamentos em sete períodos após a emergência das plântulas $(40,58$, $73,88,103,118$ e 133 dias). Os tratamentos 1 a 6 , constituíram-se de produtos comerciais usados para o manejo da mancha de ramulária, isolados ou em misturas, e o tratamento 7 é a testemunha (sem fungicida) (Tabela 1). Cada parcela foi constituída por 6 linhas de 5 $\mathrm{m}$, com $0,76 \mathrm{~m}$ de espaçamento entre linhas. Para o estabelecimento da área útil da parcela foram desprezadas as duas linhas laterais e 0,5 $\mathrm{m}$ das extremidades das quatro linhas centrais.

A semeadura foi realizada no dia 07 de fevereiro de 2014 com a cultivar de algodão FM 951 LL, na densidade de 12 plantas por metro linear. Após 15 dias do plantio, fez-se o desbaste manual para manter a população da área experimental com 9 plantas por metro linear (equivalente a 120 mil plantas ha-1).

A adubação de base foi feita de acordo com a análise do solo e recomendações de adubação da Fundação MT para uma área de primeiro de cultivo do algodoeiro. Trinta dias antes da semeadura fez-se a adubação de $90 \mathrm{~kg} \mathrm{ha}^{-1}$ de enxofre (fonte sulfurgran, $90 \%$ de S) e uma adubação potássica de $150 \mathrm{~kg} \mathrm{ha}^{-1}$ de $\mathrm{K}_{2} \mathrm{O}$ (fonte $\mathrm{KCl}, 62 \%$ de $\mathrm{K}_{2} \mathrm{O}$ ) granulado à lanço na área experimental, com equipamento motomecanizado. No sulco de semeadura foram aplicados, $154 \mathrm{~kg}$ ha $^{-1}$ de MAP $\left(12 \%\right.$ de $\mathrm{N}$ e $52 \%$ de $\left.\mathrm{P}_{2} \mathrm{O}_{5}\right)$ e $100 \mathrm{~kg} \mathrm{ha}^{-1}$ de sulfato de amônia $(21 \% \mathrm{~N}$ e $23 \% \mathrm{~S})$. Em cobertura, aplicou-se $90 \mathrm{~kg} \mathrm{ha}^{-1} \mathrm{de} \mathrm{N}$ na forma de uréia $(45 \% \mathrm{~N})$ parcelada em duas aplicações aos 40 e 60 dias após a emergência.

Foram realizadas oito aplicações dos fungicidas em intervalos de 15 dias. A primeira aplicação foi realizada aos 40 dias após a emergência (DAE), quando foi feita a primeira avaliação da doença. Os fungicidas foram aplicados a $0,5 \mathrm{~m}$ acima da cultura com um pulverizador costal pressurizado a $\mathrm{CO}_{2}$, ponta tipo leque SS DG 11002, com 3,0 bar, e vazão média de $200 \mathrm{~L} \mathrm{ha}^{-1}$.

A avaliação da severidade da doença, que ocorreu por infecção natural, foi realizada três dias após cada aplicação dos fungicidas. Estimou-se a severidade da doença nos terços inferior, médio e superior em 10 plantas da área útil de cada parcela. Para isso foi estimado o

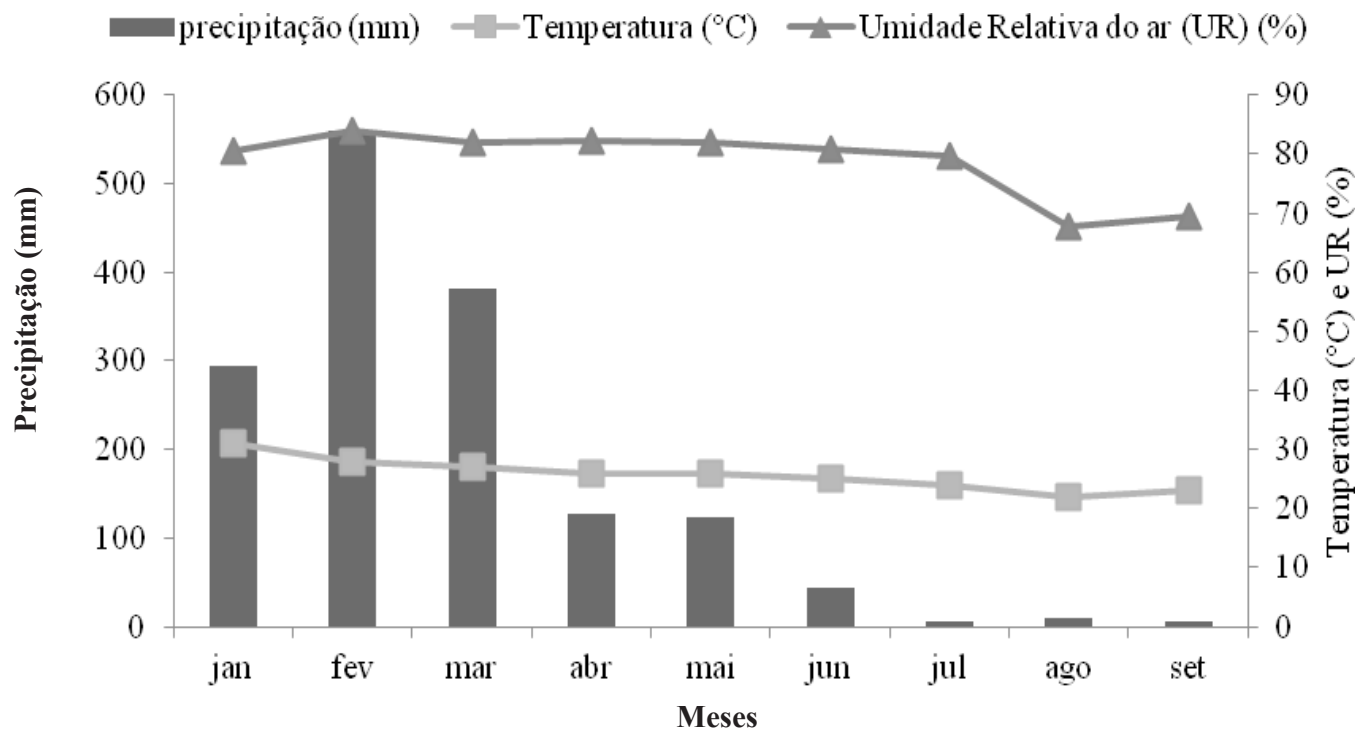

Figura 1. Precipitação pluvial, temperatura e umidade relativa do ar durante a condução do experimento. (Fonte: Fazenda Harmonia, Sapezal - MT, 2014). 
Tabela 1. Identificação dos tratamentos, dose e número de aplicações de cada fungicida usado no experimento

\begin{tabular}{|c|c|c|c|c|c|c|}
\hline \multirow[t]{2}{*}{ Trat } & \multirow[t]{2}{*}{$*$} & Produto/ Dose & * & Produto/ Dose & $*$ & Produto/Dose \\
\hline & & \multicolumn{5}{|l|}{$\mathrm{kg}$ ou L ha- } \\
\hline 1 & $8 \mathrm{x}$ & Difenoconazol 0,4 & & & & \\
\hline 3 & $8 \mathrm{x}$ & Trifloxistrobina+ Protioconazol 0,3 & & & & \\
\hline 4 & $1 \mathrm{x}$ & Difenoconazol 0,4 & $3 x$ & Trifenil Hidróxido de estanho + Difenoconazol $0,4+0,4$ & $4 \mathrm{x}$ & Difenoconazol 0,4 \\
\hline 6 & $1 \mathrm{x}$ & Difenoconazol 0,4 & $3 x$ & Mancozebe+Difenoconazol 1,5+0,4 & $4 \mathrm{x}$ & Difenoconazol 0,4 \\
\hline 7 & & Controle & & & & \\
\hline
\end{tabular}

* Número de aplicações feitas com cada produto.

percentual de tecido infectado pela mancha de ramulária e foram atribuídas notas de 1 a 5 à severidade conforme sugerido por Chitarra (5). A nota 1 foi atribuída à planta sem sintomas, nota 2 para a planta com até $5 \%$ de área foliar infectada, notas 3 ou 4 para a planta com 5 a $25 \%, 25$ a $50 \%$ com área foliar infectada, respectivamente, e nota 5 para a planta com área foliar infectada acima $50 \%$, com queda de folhas no terço médio e desfolha precoce. Aos 180 DAE, realizou-se a colheita determinando-se a produtividade de algodoeiro com caroço.

As notas foram escalonadas para valores de 0 a 100 , de modo que foi atribuído o valor de $0 \%$ de severidade à nota 1 e de $100 \%$ de severidade para a nota 5 . Os valores intermediários foram calculados proporcionalmente ao intervalo das escalas. Os valores em percentual foram utilizados para calcular os parâmetros do modelo logístico da curva de progresso da doença, conforme a Figura 2.

Onde:

y: é a severidade da doença (\%) em função do tempo (dias);

y0: representa a severidade inicial (\%);

a: é a variação entre o percentual da severidade inicial e a severidade máxima $(\%)$;

x0: é o tempo (dias) em que ocorre a máxima taxa aparente de infecção, quando também ocorre a metade da severidade máxima;

b: é um coeficiente próprio do modelo logístico, que determina incrementos crescentes de severidade no início, com uma taxa absoluta máxima quando $\mathrm{x}=\mathrm{x} 0$ e determina o ponto de inflexão da curva, onde y é igual à metade da severidade máxima.

I: é a inclinação da curva no ponto de inflexão e representa a máxima taxa de infecção da doença.

(a+yo): é severidade máxima da doença.

O modelo logístico foi escolhido com base na forma da curva da derivada $(d y / d t)$, estimativas do desvio padrão dos parâmetros xo e b e pela plotagem do resíduo padrão ( $x$ observado menos $x$ predito) em função do tempo. Adicionalmente, a escolha do modelo foi relacionada à sua interpretação biológica, pois a velocidade de aumento da doença $d y / d t$ é proporcional à própria quantidade de doença y e à quantidade de tecido sádio disponível (1-x).

A eficiência dos fungidas no controle da severidade da mancha de ramulária foi calculada pela diferença entre a integral definida no período 0 a 180 dias da severidade do tratamento 7 (testemunha) e a integral definida no mesmo período, para a severidade de cada tratamento com os fungicidas, conforme a equação 1 .

Os dados de severidade da mancha da ramulária e de produtividade foram submetidos à análise de variância e as médias comparadas através do teste de Scott-Knot ao nível de 0,05 de probabilidade.

Eficiência do fungicida $=\int_{0}^{180}$ (testemunha) $\mathrm{dx}-\int_{0}^{180}$ (tratamento) $\mathrm{dx}$

\section{RESULTADO E DISCUSSÃO}

Houve interação significativa dos tratamentos com fungicidas com o tempo sobre severidade da mancha da ramulária e produtividade do algodoeiro. Durante o período experimental,

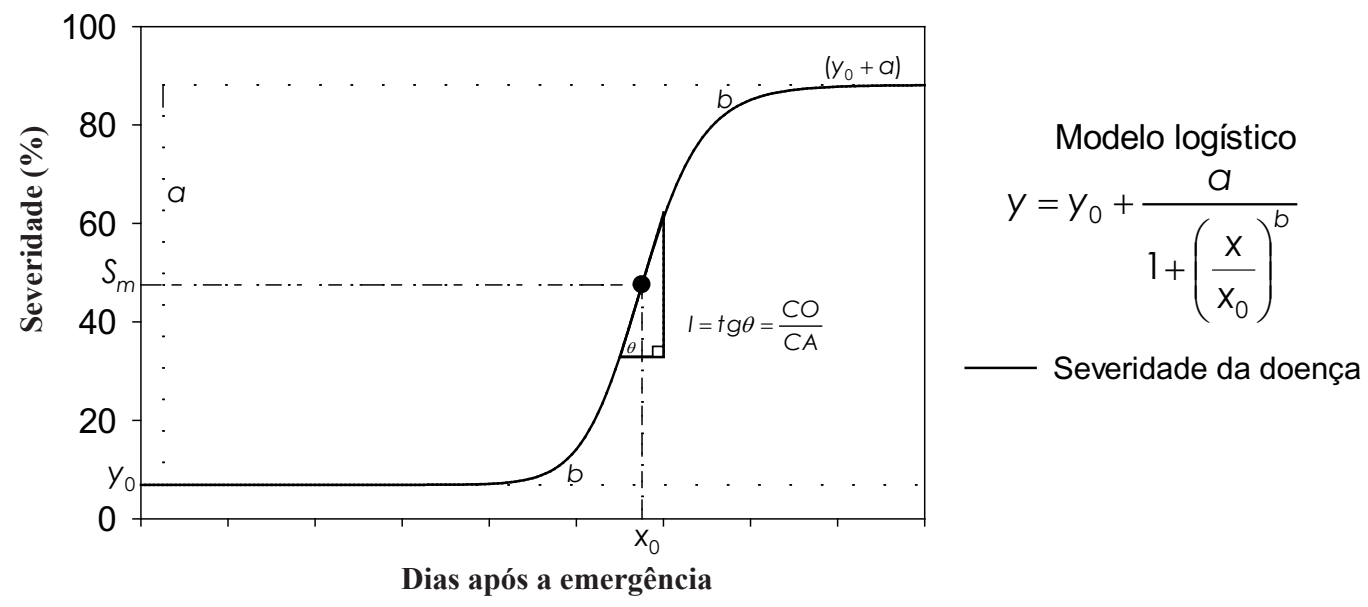

Figura 2. Curva de progresso da doença conforme o modelo logístico. 
a temperatura variou entre 22 e $31^{\circ} \mathrm{C}$, com média de $25,7^{\circ} \mathrm{C}$. A precipitação pluvial e umidade relativa apresentaram valores médios de $172 \mathrm{~mm}$ e 78,5\%, respectivamente (Figura 1). Estas condições ambientais favoreceram o processo infeccioso da mancha de ramulária (11). Outros autores também relatam que as condições ambientais aliadas ao uso de cultivares suscetíveis proporcionam uma maior severidade de doenças causadoras de manchas foliares, nas principais áreas produtoras de algodão $(2,12)$.

$\mathrm{Na}$ primeira e segunda avaliação não foram observadas diferenças significativas nas notas de severidade da mancha da ramulária entre os tratamentos, o que está relacionado ao menor sombreamento no início do desenvolvimento vegetativo da cultura, à fonte de inoculo do patógeno e à tolerância da cultivar à infecção $(7,9,6)$ (Figura 3). Outros autores também encontraram baixa severidade da mancha da ramulária aos 66 DAE (2). A infecção da mancha da ramulária no campo está associada aos ascósporos bem como aos conídios produzidos pelas plantas voluntárias e a propagação secundária da doença aos conídios transportados pelo ar de $R$. aréola, o que enfatiza a necessidade de desenvolver medidas apropriadas para eliminar o inóculo do $M$. areola no solo (13).

A partir da terceira avaliação observou-se diferença entre os valores de severidade da doença entre os tratamentos, com aumento gradativo em todos os tratamentos nas sete avaliações. A partir da quarta avaliação, os tratamentos 2 e 4 que continham trifenil hidróxido de estanho foram os que obtiveram as menores notas de severidade (Tabela 4). Houve maior diferença entre os tratamentos aos 118 dias DAE, comparando com os valores 133 DAE, o que demonstra a ação dos fungicidas em retardar a maior infestação do patógeno dependendo do mecanismo de ação.

O tratamento 3 (trifloxistrobina + protioconazol), associação de uma estrobilurina com um triazol, obteve o pior desempenho entre os fungicidas avaliados, sem diferença significativa dos valores de severidade em relação à testemunha em seis das sete avaliações realizadas. Ressalta-se que este fungicida está registrado no mistério da agricultura do Brasil para o controle da mancha da ramulária. No entanto, os fungicidas de estrobilurina são classificados pelo comitê de ação de resistência à fungicida, como tendo um alto risco para o desenvolvimento de resistência após 2 a 10 anos da introdução do produto comercial na área, enquanto o protioconazol (triazol) é classificado como de médio risco de resistência $(3,15)$.

Os tratamentos 1,5 e 6 obtiveram desempenho intermediário no controle da severidade da mancha da ramulária entre os fungicidas avaliados. Os três tratamentos contêm difenoconazol, fungicida do
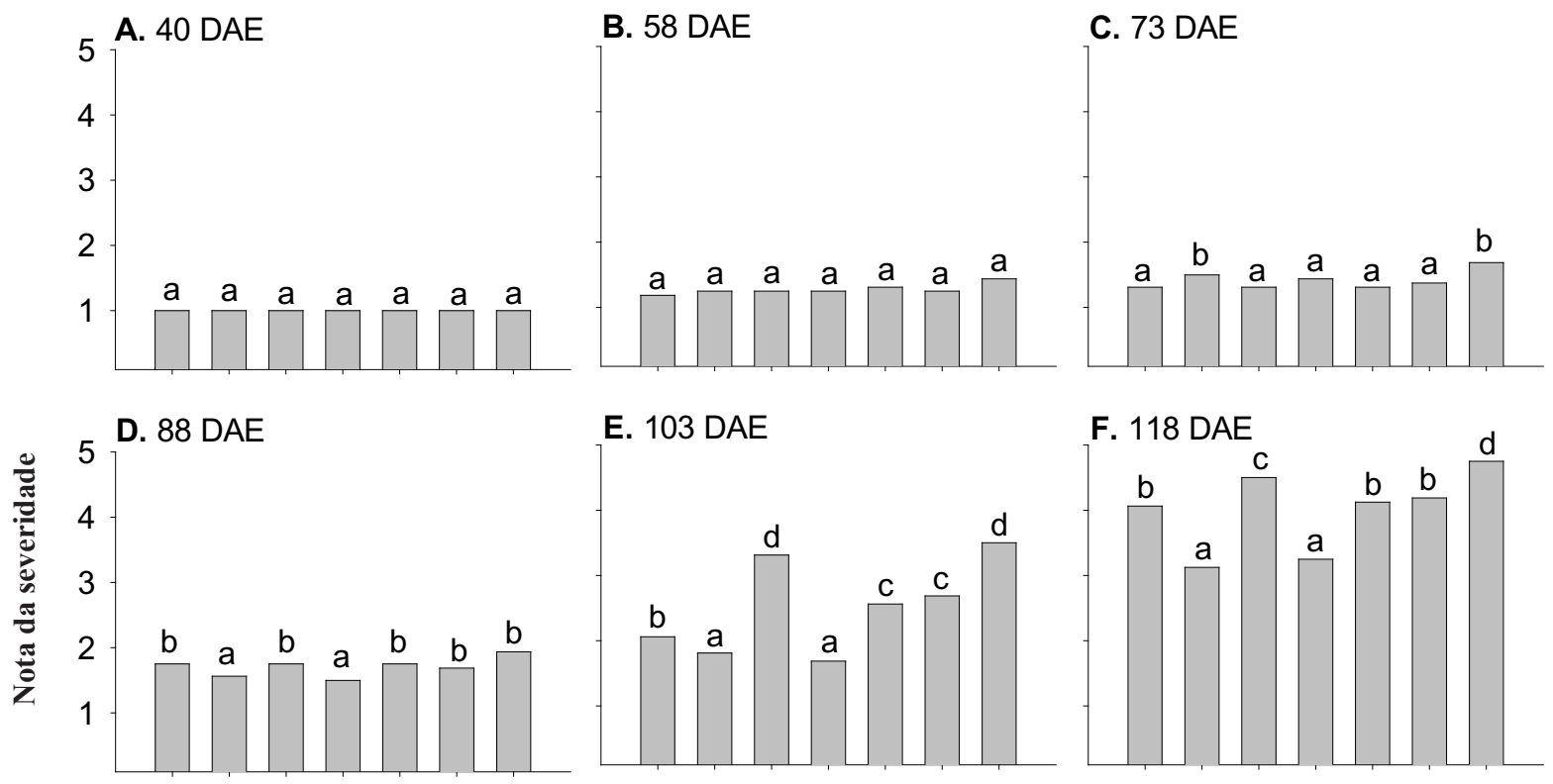

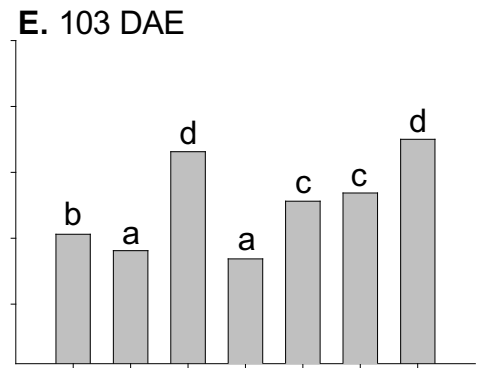

$\begin{array}{lllllll}\text { T1 } & \text { T2 } & \text { T3 } & \text { T4 } & \text { T5 } & \text { T6 } & \text { T7 }\end{array}$

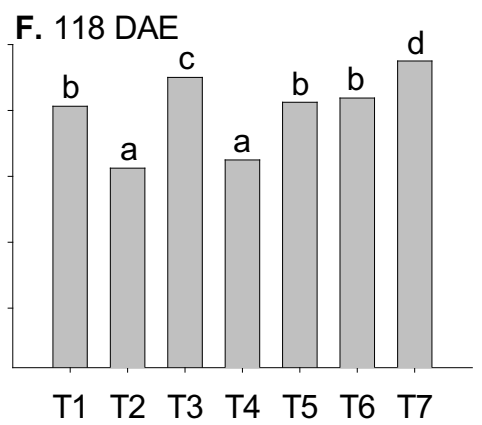

\section{G. $133 \mathrm{DAE}$}

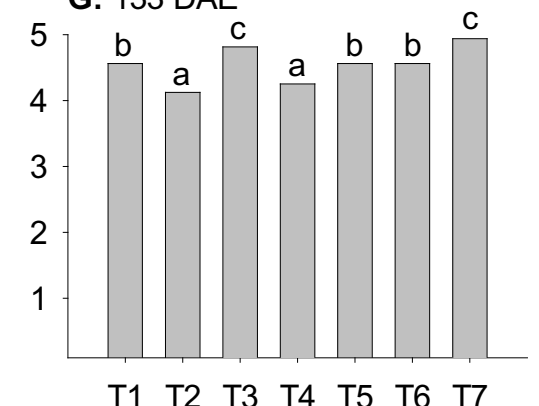

$\begin{array}{lllllll}\text { T1 } & \text { T2 } & \text { T3 } & \text { T4 } & \text { T5 } & \text { T6 } & \text { T7 }\end{array}$

Tratamentos

Figura 3. Severidade de Ramularia areola aos 40, 58, 73, 88, 103, 118 e 133 dias após a emergência (DAE). 
Tabela 2. Parâmetros do modelo logístico ( $\mathrm{a}, \mathrm{b}, \mathrm{x} 0$ e y0), inclinação no ponto de inflexão da curva de progresso da doença ou máxima taxa de infecção (I) e coeficiente de determinação $\left(\mathrm{R}^{2}\right)$ para a severidade da mancha de ramulária na cultura do algodoeiro após a aplicação de fungicidas.

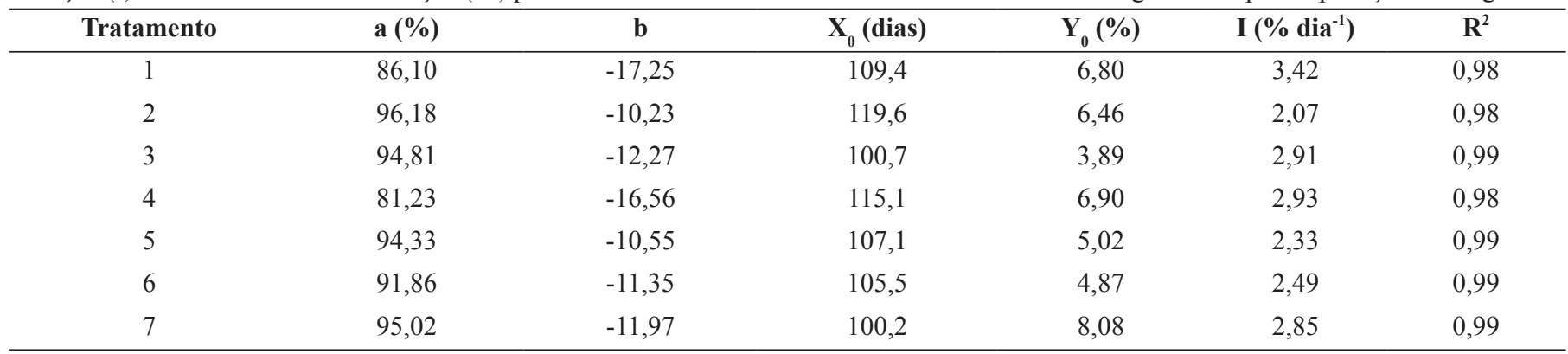

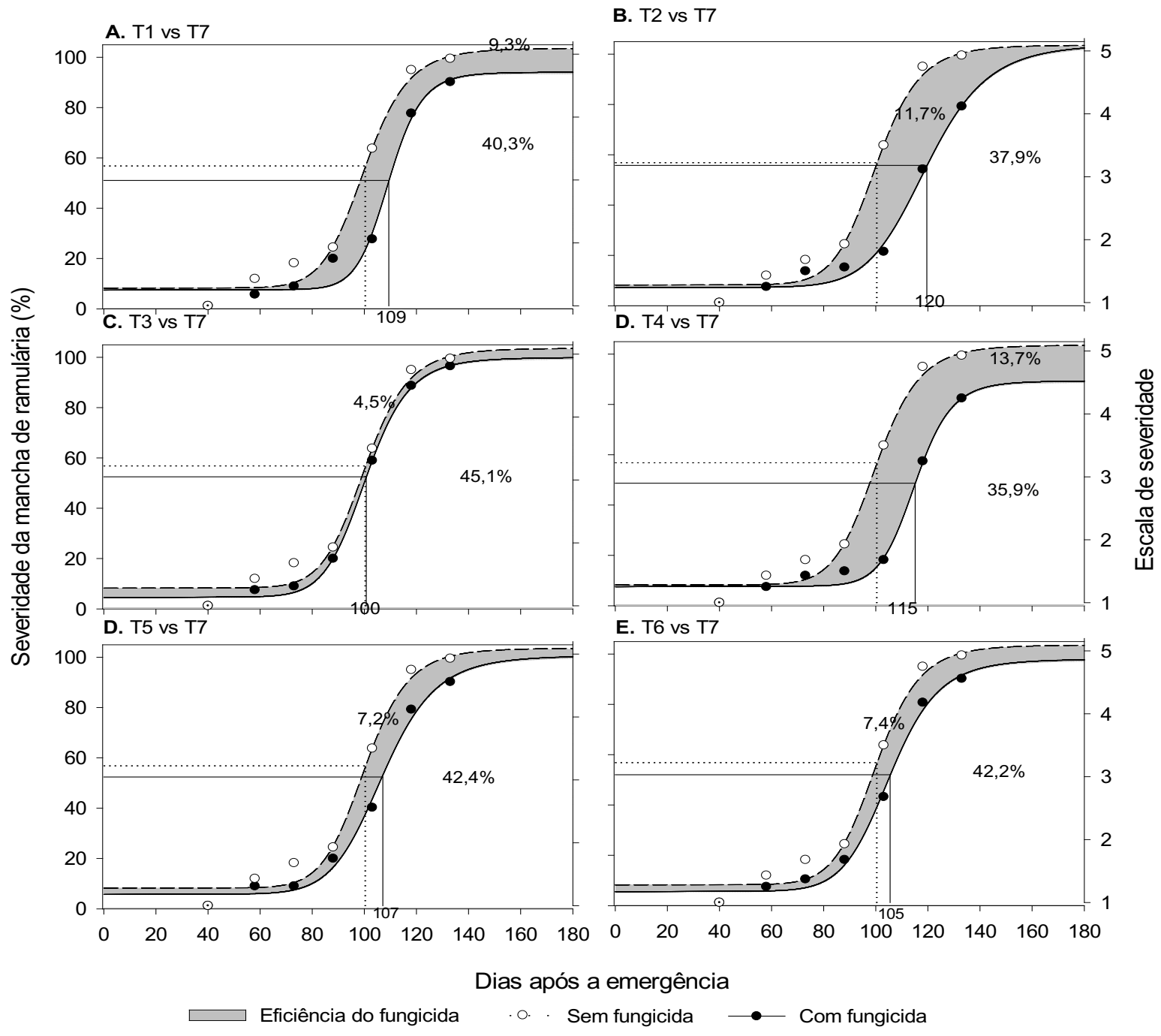

Figura 4. Curvas de progresso da mancha de ramulária para cada tratamento em relação à testemunha (sem aplicação de fungicida). A eficiência do tratamento é a integral da severidade da doença em função do tempo da testemunha menos a integral da severidade da doença do fungicida avaliado. A descrição dos fungicidas usados em cada tratamento está na tabela 1.

grupo dos triazóis que age na inibição da demetilação de $\mathrm{C}$ na biossíntese de esteróis fúngicos (19). O tratamento 5 também é uma associação de triazóis com estrobilurina (difenoconazol e trifloxistrobina + protioconazol), sendo que os dois triazóis pertencem ao mesmo grupo, pois ambos são de inibidores da demetilação. O baixo nível de controle dos tratamentos 1 e 5 pode estar relacionado desenvolvimento de resistência cruzada entre os triazóis, por outro lado, o tratamento 6, apesar de ter sido aplicado o mancozebe, fungicida de ação múltipla, também não foi eficaz no controle da mancha da ramulária.

Apesar do experimento ter sido conduzido em uma área de 


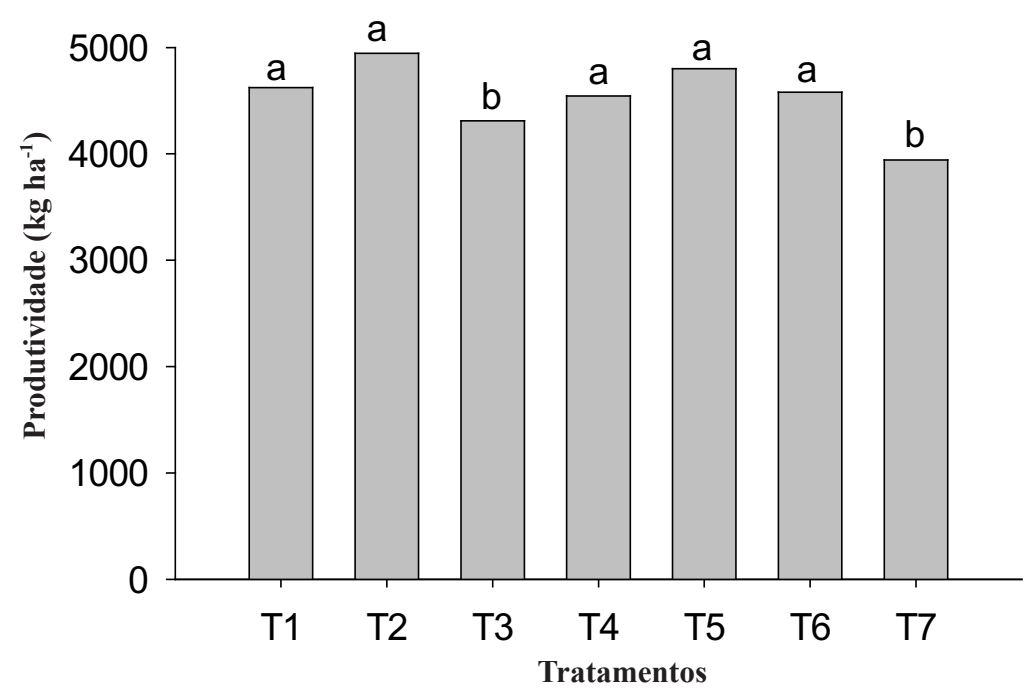

Figura 5. Produtividade do algodoeiro com caroço em função da aplicação de fungicidas para o controle da mancha de ramulária. Médias com mesma letra, na coluna, não diferem entre si pelo teste de Skott-Knott ao nível de 0,05 de probabilidade.

primeiro ano de cultivo de algodão, é possível que a baixa eficiência dos fungicidas dos tratamentos 1, 3, 5, 6 esteja relacionada ao emprego contínuo das estrobilurinas e triazóis nas áreas vizinhas à área experimental. O surgimento de indivíduos resistentes às moléculas dos grupos dos benzimidazóis e triazóis aumenta a necessidade por estratégias antirresistência e por novas moléculas com mecanismo de ação não sítio-específico $(20,22,24)$.

A comparação do parâmetro $\mathrm{X}_{0}$ das curvas de progresso da severidade da mancha de ramulária nos tratamentos mostraram que exceto o tratamento 3 , os demais retardaram o período para a ocorrência da metade da severidade máxima em relação à testemunha (Tabela 2). A inclinação da curva no ponto de inflexão (I), que representa a taxa máxima de infecção, foi menor no tratamento 2 (trifenil hidróxido de estanho) em relação aos demais tratamentos, o que indica maior controle da infecção. Além disso, este tratamento também se destacou em retardar o progresso da doença em 20 dias em relação à testemunha, parâmetro $\mathrm{X}_{0}$. $\mathrm{O}$ tratamento 4 (difeconazol + trifenil hidróxido de estanho) também se destacou positivamente em relação ao controle da severidade da ramulária, nota-se que o parâmetro a, que representa a variação entre a severidade inicial e final, foi menor no tratamento 4 em relação aos demais.

Ao se calcular a área abaixo da curva do progresso da doença para cada tratamento em relação à testemunha é possível identificar os tratamentos com maior eficiência de controle da mancha de ramulária (Figura 4). A ordem decrescente da eficiência de controle da mancha de ramulária T2 $>\mathrm{T} 4>\mathrm{T} 1>\mathrm{T} 6>\mathrm{T} 5>\mathrm{T} 3$ com 13,7, 11,7, 9,3, 7,4, 7,2 e $4,5 \%$ respectivamente.

As maiores perdas em produtividades foram obtidas nos tratamentos 3 e 7, testemunha e fungicida trifloxistrobina + protioconazol, respectivamente, os demais tratamentos avaliados apresentaram produtividade maior que a da testemunha, mas não diferiram entre si (Figura 5). Este resultado está associado com a maior severidade da mancha de ramulária nos tratamento 3 e 7 , como resultado de uma diminuição da capacidade fotossintética da planta em virtude da destruição dos tecidos das folhas (7). Por outro lado, a literatura relata que a redução da severidade da mancha da ramulária, pela aplicação do fungicida triazol, tetraconazole, pode não interferir na produtividade do algodoeiro (18).
Outros autores também relataram os benefícios do uso de fungicidas com diferentes princípios ativos, principalmente os grupos químicos das estrobilurinas e triazóis, usados tanto isolados quanto em misturas $(21,1)$. Também tem sido relatada, a maior eficiência da mistura dos fungicidas mancozebe e triazol em comparação com fungicidas aplicados isoladamente $(1,4)$. O controle químico tem sido a medida mais utilizada pelos produtores na região Centro-Oeste do Brasil para reduzir o inóculo $R$. areola (16).

O uso de fungicidas é a medida mais rápida e eficiente no controle de doenças fúngicas, evitando a perda do rendimento das culturas. O controle químico tem sido uma das estratégias de manejo que reduzem a taxa de progresso da doença no campo. Os fungicidas têm contribuído para reduzir os danos na produtividade, principalmente devido à manutenção área foliar durante o enchimento do capulho, ou ainda através de efeitos diretos dos fungicidas na fisiologia da planta (22).

Dessa forma, o presente trabalho indica novas alternativas para o controle da mancha de ramulária mediante a aplicação de trifenil hidróxido de estanho isoladamente ou em combinação com difenoconazol. As combinações dos fungicidas, além de propiciarem o controle da doença, representam uma estratégia importante a ser adotada, a fim de evitar os mecanismos de resistência do fungo.

A aplicação de fungicidas reduz danos causados pelo fungo Ramularia areola na cultura do algodoeiro.

O fungicida trifenil hidróxido de estanho isolado ou em mistura com o difenoconazol é mais eficiente na redução da severidade da mancha de ramulária do algodoeiro do que a mistura trifloxistrobina + protioconazol com difenoconazol, ou difenoconazol com mancozebe nas condições do ambiente em estudo.

\section{REFERÊNCIAS:}

1. Aquino, L.A.; Berger, P.G.; Rodrigues, F.A.; Zambolim, L.; Ogoshi, F.; Miranda, L.M.; Lélis, M.M. Controle alternativo da mancha de Ramularia do algodoeiro. Summa Phytopathologica, Botucatu, v. 34, n. 2, p. 131136, 2008.

2. Barros, R.; Degrande, P.E.; Soria, M.F; Ribeiro, J.S.F. Ocorrência de manchas foliares causadas por fungos e bactéria em cultivares de algodoeiro. Pesquisa Agropecuária Brasileira, Brasília, v.38, n.4, p.297-303, 2008. 3. Brent, K.J.; Hollomon, D.W. Fungicide resistance: the assessment of risk. 
Brussels: Fungicide Resistance Action Committee, 2007. v.1, 224p.

4. Cassetari Neto, D.; Andréia Quixabeira Machado, A.Q.; Andrade Júnior, E.R.; Vidotti, E.D.; Rivelini, V.E.; Garcia, A.R.; Oliveira, A.S. Programas de aplicação de fungicidas no controle de ramulose (Colletotrichum gossypii var. cephalosporioides) e mancha de ramularia (Ramularia areola) em algodoeiro no Mato Grosso. In: II Congresso Brasileiro de Algodão, 2009, Foz do Iguaçu. Anais. Campina Grande: EMBRAPA Algodão, 2009. p. 1122-1128.

5. Chitarra, L.G.; Barbosa, C.A.S.; Pedrosa, M.B. Controle químico da mancha de ramulária do algodoeiro no oeste da Bahia. In. In: Silva Filho, J.L.; Pedrosa, M.B. Pesquisas com Algodoeiro no Estado da Bahia Safra 2006/2007. Campina Grande: Embrapa Algodão, 2008. p. 59-72.

6. Cia, E.; Fuzatto, M.G; Kondo, J.I.; Ohl, G. de A.; Galbieri, R. Reação de genótipos de algodoeiro à mancha de ramulária em diferentes épocas e ambientes. Summa Phytopathologica, Botucatu, v.39, n.3, p.193-197, 2013.

7. Cia, E.; Salgado, C.L.; Doenças do algodoeiro (Gossypium spp.). In: H. Kimati, H.; Amorim, L.; Bergamin Filho, A.; Camargo, L.E.A.; J.A.M. Rezende, J.A.M. Manual de fitopatologia: doenças das plantas cultivadas. São Paulo: Ceres, 1997, v.2, cap.6, p.40-54.

8. Galbieri, R.; Cia, E.; Morello, C.L.; Fanan, S.; Andrade Junior, E.R.; Kobayasti, L. Ramularia areola sporulation potential in Brazilian cotton. Summa Phytopathologica, Botucatu, v.41, n.3, p.233-235, 2015.

9. Girotto, L.; Marangoni, M.S.; Matos, J.N.; Galbieri, R.; Almeida, W. P.; Mehta, Y.R. Identification of Phenotypic and Genotypic Variability among the Isolates of Ramularia areola of Brazilian Cotton. American Journal of Plant Sciences, Wuhan, v.4, n.9, p.1893-1898, 2013.

10. Gisi, U.; Leadbeater, A. The challenge of chemical control as part of inf tegrated pest management. Journal of Plant Pathology, Bari, v.92, n.4, p.12-15, 2010.

11. Johnson, I.; Ramjegathesh, R.; Karthikeyan, M.; Chidambaram, P. Epidemiology of grey mildew and Alternaria blight of cotton. Archives of Phytopathology and Plant Protection, Berlin, v. 46, n. 18, p. 2216-2223, 2013.

12. Lima, L.L. de; Barreto, M.; Scaloppi, A.G. Reação de cultivares de algodoeiro a Ramularia areola. Summa Phytopathologica, Botucatu, v.36, n.1, p.57-60, 2010.

13. Mehta, Y.; Galbieri, R.; Marangoni, M.S.; Borsato, L.C.; Rodrigues, H.P.; Pereira, J.; Mehta, A. Mycosphaerella areola-The Teleomorph of Ramularia areola of Cotton in Brazil, and Its Epidemiological Significance. American
Journal of Plant Sciences, Wuhan, v. 7, n.10, p. 1415-1422, 2016.

14. Novaes, T.G.; Almeida, W.P.; Schuster, I.; Aguiar, P.; Mehta, Y.R. Herança de resistência do algodoeiro a Ramularia areola. Summa Phytopathologica, Botucatu, v.37, n.2, p.150-152, 2011.

15. Parreira, D.F.; Neves, W. dos S.; Zambolim, L. Resistência de Fungos a Fungicidas Inibidores de Quinona. Revista Trópica - Ciências Agrárias e Biológicas, São Luis, v.3, n.2, p.24-34. 2009.

16. Pizzato, J.A.; Araújo, D. V.; Serafim, M.E.; Araújo, K.L.; Dallacort, R.; Gílio, A. S.; Romano Jr., J.; Maciel, V.A. Epidemiologic study of Ramularia areola under different soil covers and spacings, for cotton crops. American Journal of Plant Sciences, Irvine, v. 4, n.11, p.2049-2059, 2013.

17. Santos, H.G; Jacomine, P.K.T.; Anjos, L.H.C.; Oliveira, V.A.; Lumbreras, J.F.; Coelho, M.R.; Almeida, J.A.; Cunha, T.J.F.; Oliveira, J.B. Sistema Brasileiro de Classificação de solos. 3.ed. rev. ampl. Brasília, DF: EME BRAPA, 2013. 353 p.

18. Silva, J.C.; Suassuna, N.D.; Bettiol, W. Management of ramularia leaf spot on cotton using integrated control with genotypes, a fungicide and Trichoderma asperellum. Crop Protection, Amsterdam, v. 94, n. 1, p. 28-32, 2017.

19. Stenzel, K. Overview on sterol biosynthesis inhibitors. In: Fungicide Resistance Action Committee: working group. Monheim, 2017. Disponível em: $<$ http://www.frac.info/working-group/sbi-fungicides $>$. Acesso em: 14 abr. 2017.

20. Suassuna, N.D.; Coutinho, W.M.; Ferreira, A.C.B. Manejo da Mancha de Ramulária em Algodoeiro. EMBRAPA, CNPA, Campina Grande. Comunicado Técnico n. 272, 2006. 4 p.

21. Woodward, J.E.; Dodds, D.M.; Main, C.L.; Barber, L.T.; Boman, R.K.; Whitaker, J.R.; K.L.; Banks, E.J.C.; Buehring, N.W.; Allen, T.W. Evaluation of foliar applications of strobilurin fungicides in cotton across the Southern United States. Journal of Cotton Science, Baton Rouge, v.20, n.2, p.116-124, 2016.

22. Zancan, W.L.; Chitarra, L.G.; Chitarra, G.S. Cotton in Brazil: importance and chemical control of bolls rot. In. Nita, M. Fungicides - Showcases of Integrated Plant Disease Management from Around the World. Rijeka: InTech, 2013. p. 135-152.

23. Zandona, C.I.; Novaes, T.G.I.; Nunes, M.P.I.; Almeida, W.P.I.; Aguiar, P.H.; Morello, C.L.; Shuster, W.P.I.; Mehta, Y.R. Mechanism of resistance and presence of different resistance genes to Ramularia areola in two cotton genotypes. Tropical Plant Pathology, Viçosa, v.37, n.3, p.175-178, 2012. 